\title{
Subclinical Posttraumatic Stress Disorder Symptoms: Relationships with Blood Pressure, Hostility, and Sleep
}

\author{
James A. McCubbin, ${ }^{1,2}$ Heidi M. Zinzow, ${ }^{1,2}$ Melissa A. Hibdon, ${ }^{1}$ Aaron W. Nathan, ${ }^{1}$ \\ Anastasia V. Morrison, ${ }^{3}$ Gregg W. Hayden, ${ }^{1}$ Caitlyn Lindberg, ${ }^{3}$ and Fred S. Switzer ${ }^{1}$ \\ ${ }^{1}$ Clemson University, Clemson, SC 29634, USA \\ ${ }^{2}$ University of South Carolina School of Medicine, Greenville, SC 29605, USA \\ ${ }^{3}$ University of South Carolina School of Medicine, Columbia, SC 29209, USA \\ Correspondence should be addressed to James A. McCubbin; jmccubb@clemson.edu
}

Received 30 March 2016; Accepted 25 May 2016

Academic Editor: Koichi Hirata

Copyright (C) 2016 James A. McCubbin et al. This is an open access article distributed under the Creative Commons Attribution License, which permits unrestricted use, distribution, and reproduction in any medium, provided the original work is properly cited.

\begin{abstract}
The purpose of this study was to examine the relationships among subclinical PTSD symptoms, blood pressure, and several variables linked to both frank PTSD and the basic psychobiological adaptation to stress. The authors recruited a sample of 91 healthy, young men and women between 18 and 35 years. We examined links among subclinical posttraumatic stress disorder symptoms, blood pressure, sleep quality, and hostility. Posttraumatic stress disorder symptoms were associated with poorer sleep quality and higher hostility scores in both women and men. In men, PTSD symptoms were also associated with elevated resting diastolic blood pressure, and sex was an important moderator of that relationship. Moreover, sleep quality and hostility are substantive mediators of the relationship between diastolic blood pressure and PTSD. Behavioral interventions designed to increase sleep quality and restructure hostile attitudes could potentially serve as preventive interventions for PTSD and the underlying cardiovascular comorbidities in young adults.
\end{abstract}

\section{Introduction}

The clinical symptomology of posttraumatic stress disorder (PTSD) and the psychobiology of stress and arousal are intimately related. For example, both PTSD and psychological stress are associated with alterations in autonomic, circulatory, and behavioral mechanisms. Patients diagnosed with PTSD often exhibit hyperarousal, blood pressure dysregulation, sleep disruption, and elevated levels of hostility [16]. These symptoms are not uncommon during psychological stress in persons without a history of PTSD [7-10], but the precise relationship between the normal, psychobiological adaptations to stress and the expression of PTSD psychoand physiopathology is not well characterized, especially in young adults. The purpose of this study was to examine, in young men and women, the relationships among subclinical PTSD symptoms and several variables linked to both frank PTSD and the basic psychobiological adaptation to stress, including blood pressure, sleep quality, and hostility. If factors associated with chronic arousal and adaptation to stress are associated with subclinical PTSD-like symptoms, then it may be possible to better understand precursors and potential new preventive and treatment strategies for persons with frank PTSD and its underlying cardiovascular comorbidities in healthy, young adults.

The Psychobiology of Stress. Adaptation to acute and chronic psychological stress is accompanied by alterations in the sympathoadrenomedullary and the hypothalamic pituitary adrenocortical systems, with the consequent neuroendocrine cascade affecting blood pressure and a variety of other critical bodily functions. Several factors can influence the magnitude of these changes, including genetic, behavioral, and situational factors. For example, a meta-analysis by $\mathrm{Wu}$ et al. [11] found pooled heritability estimates for circulatory stress reactivity ranging from 0.21 to 0.55 . Behavioral factors such as hostility have been shown to increase blood pressure during stress [12]. Situational factors influencing stress 
responsivity include demand, control, and predictability [13]. Moreover, lifestyle and activities also have a significant impact on responses to stress, including aerobic fitness [14] and, importantly, sleep deprivation [15].

The Psychobiology of PTSD. PTSD is one potential outcome of extreme stress exposure characterized by autonomic dysregulation, increased cardiovascular reactivity, hyperarousal, sleep disturbances, and hostility. According to DSM-5 criteria, PTSD consists of four clusters of symptoms: (1) intrusion (e.g., intrusive memories); (2) avoidance; (3) negative alterations in cognitions and mood; and (4) alterations in arousal and reactivity [1]. In particular, the arousal and reactivity symptoms may consist of irritable, aggressive, or hostile behavior, hypervigilance, exaggerated startle response, blood pressure dysregulation, and sleep disturbance. Persons with PTSD show a number of psychobiological adaptations that overlap and perhaps interact with the response to nontraumatic acute and chronic stress. Exposure to adverse experiences, including abuse in childhood and adult trauma, can alter neuroendocrine stress reactivity [16]. Moreover, studies of combat veterans with PTSD show alterations in opioidergic mechanisms influencing pain sensitivity as well as blood pressure reactivity $[17,18]$. Common risk factors for PTSD are prior trauma, acute stress symptoms, and autonomic hyperarousal, among others [19].

PTSD is associated with catecholamine, serotonin, and hypothalamic pituitary axis (HPA) dysregulation, which contributes to increased sympathetic and circulatory reactivity in response to stressful demands [18, 20, 21]. Researchers hypothesize that PTSD involves chronic overactivation of the sympathetic nervous system [22]. It is therefore not surprising that individuals with PTSD exhibit higher baseline heart rate, blood pressure, and higher incidence of hypertension in comparison to individuals without PTSD [3, 23, 24].

Although hyperarousal and stress reactivity likely represents a mechanistic link between PTSD and blood pressure dysregulation, precise etiologic mechanisms underlying this relationship have not been pointedly examined. Several constructs have been investigated independently as risk factors for hypertension and/or blood pressure dysregulation, including stress reactivity, hostility, and sleep disturbance. Hostility, for example, has been linked to blood pressure control mechanisms [24], risk for coronary heart disease [25], and PTSD [5]. In addition, Beckham and coworkers [24] found that hostile beliefs in women with PTSD were associated with increases in ambulatory blood pressure.

Thus, blood pressure dysregulation, hostility, and sleep disturbances are associated with frank PTSD, as well as responses to stress in persons without a PTSD history. Even though PTSD symptom clusters are generally employed to classify individuals who have been exposed to traumatic events, current research has not fully examined the relationships among those factors in persons without a history of PTSD. Better understanding of the normal relationships among subclinical PTSD symptoms, blood pressure, sleep quality, and hostility in young healthy populations may provide insight into the psycho- and physiopathology underlying adaptations to traumatic stress.

\section{Methods}

2.1. Sample and Procedure. Participants between 18 and 35 years of age (average $\pm \mathrm{SE}=21.4 \pm 0.45$ ) provided resting blood pressure levels in a laboratory setting and then completed a series of self-report questionnaires. Participants included a sample of 91 young men $(n=42)$ and women $(n=49)$ recruited from the local geographical area. The final sample was 73.1\% white, 9.7\% black, 9.7\% Asian. Exclusion criteria were history of significant cardiovascular, endocrine, or psychiatric disorder including PTSD or current use of cardiovascular or psychoactive medications.

All procedures were approved by the Institutional Review Board for protection of human research participants, and written informed consent was obtained from all individual participants included in the study. Then, participants were assessed for resting systolic blood pressure (SBP) and diastolic blood pressure (DBP) both sphygmomanometrically and with a calibrated GE Dinamap Pro100V2 automated oscillometric device (GE Medical Systems Information Technologies, Inc., Milwaukee, WI). Dinamap performance was verified on a regular basis for zero offset, integral offset, and gain using a mercury manometer. All resting blood pressure measurements used American Heart Association guidelines for blood pressure determination [26]. Resting blood pressure was determined after a 5 min rest while sitting upright in a comfortable arm chair. For analysis of resting blood pressure, five automated readings of blood pressure and heart rate $(\mathrm{HR})$ were taken at $2 \mathrm{~min}$ intervals. The last three automated readings were averaged for analysis to allow stabilization and minimize initial responses to the blood pressure measurement procedure. Participants then completed the PTSD Checklist [27], Pittsburgh Sleep Quality Index (PSQI) [28], and the Cook-Medley Hostility Scale [29].

\subsection{Measures}

PTSD Checklist. The civilian version of the PTSD Checklist is a 17-item rating scale incorporating self-report of distress over the past 30 days based on accepted PTSD diagnostic criteria [30]. This scale has been shown to be psychometrically sound for internal consistency, test-retest reliability, discriminant validity, and convergent validity [30,31]. It has been validated in multiple populations, including motor vehicle accident victims, primary care patients, and community members $[32,33]$.

Pittsburgh Sleep Quality Index. The PSQI is one of the most widely used instruments to measure sleep quality, insomnia, and daytime sleepiness. The PSQI has been systematically evaluated for sensitivity and specificity for sleep disorder screening, is highly related to sleep diary data, and has been assessed in both population-based and clinical studies [28]. PSQI scores are sensitive to blood pressure and catecholamine levels in hypertensive patients [34].

Cook-Medley Hostility Scale. The Cook-Medley Hostility Scale is a widely used self-report assessment including suspiciousness, resentment, and cynical mistrust, rather than overt 
TABLE 1: Descriptive statistics for the total sample and for men and women separately.

\begin{tabular}{|c|c|c|c|c|c|c|}
\hline & \multirow{2}{*}{$\begin{array}{c}N \\
\text { Statistic }\end{array}$} & \multirow{2}{*}{$\begin{array}{c}\text { Minimum } \\
\text { Statistic }\end{array}$} & \multirow{2}{*}{$\begin{array}{c}\text { Maximum } \\
\text { Statistic }\end{array}$} & \multicolumn{2}{|c|}{ Mean } & \multirow{2}{*}{$\begin{array}{c}\text { Std. deviation } \\
\text { Statistic }\end{array}$} \\
\hline & & & & Statistic & SE & \\
\hline \multicolumn{7}{|c|}{ Total sample } \\
\hline Age & 89 & 18 & 52 & 21.40 & .454 & 4.285 \\
\hline Sleep quality & 91 & 1 & 14 & 4.82 & .283 & 2.702 \\
\hline $\mathrm{DBP}$ & 91 & 53.7 & 84.0 & 67.564 & .6004 & 5.7272 \\
\hline SBP & 91 & 86.3 & 141.7 & 113.689 & 1.2971 & 12.3738 \\
\hline PTSD symptoms & 92 & 9 & 61 & 28.32 & 1.098 & 10.535 \\
\hline Hostility & 89 & 4 & 37 & 19.24 & .775 & 7.307 \\
\hline \multicolumn{7}{|c|}{ Men } \\
\hline Age & 42 & 18 & 33 & 21.69 & .490 & 3.174 \\
\hline Sleep quality & 42 & 1 & 14 & 4.86 & .452 & 2.927 \\
\hline $\mathrm{DBP}$ & 42 & 57.0 & 84.0 & 67.876 & .9188 & 5.9544 \\
\hline SBP & 42 & 99.3 & 141.7 & 121.090 & 1.4448 & 9.3636 \\
\hline PTSD symptoms & 41 & 17 & 61 & 29.56 & 1.876 & 12.011 \\
\hline Hostility & 41 & 6 & 37 & 21.51 & 1.170 & 7.490 \\
\hline \multicolumn{7}{|c|}{ Women } \\
\hline Age & 47 & 18 & 52 & 21.15 & .744 & 5.099 \\
\hline Sleep quality & 49 & 1 & 14 & 4.80 & .361 & 2.525 \\
\hline $\mathrm{DBP}$ & 49 & 53.7 & 80.3 & 67.296 & .7962 & 5.5731 \\
\hline SBP & 49 & 86.3 & 139.3 & 107.345 & 1.5855 & 11.0983 \\
\hline PTSD symptoms & 49 & 9 & 58 & 27.49 & 1.332 & 9.325 \\
\hline Hostility & 48 & 4 & 35 & 17.29 & .956 & 6.620 \\
\hline
\end{tabular}

aggressive behaviors $[29,35]$. Persons with high levels of hostility show increased blood pressure responses to stress and increased anger $[12,35]$. The Cook-Medley Hostility Scale has been shown to have good convergent and discriminant validity and has been linked to coronary heart disease and all-cause mortality [29].

2.3. Statistical Analysis. Results were analyzed using SPSS for descriptive statistics and linear regression analyses. These data were analyzed for the total group and for men and women separately. Regression analyses utilized PTSD symptoms as the dependent variable, with age, sex, blood pressure, hostility, and sleep quality as independent variables. Mediation and moderation were assessed by the moderated causal steps approach [36].

\section{Results}

Table 1 shows descriptive statistics for the total sample and separately for men and women. The present sample of young adults averaged $21.4 \pm 0.45$ years of age (mean \pm SE). Men averaged 21.7 years while women averaged 21.2 years, with no significant sex differences. Average blood pressure in the total study sample was $113.7 \pm 1.30 \mathrm{mmHg}$ for systolic and $67.6 \pm 0.60$ for diastolic blood pressure. The average SBP for men was $121.1 \pm 1.50$ while women averaged $107.4 \pm$ $1.59 \mathrm{mmHg}$, and this difference was statistically significant $(p<.001)$. There were no significant sex differences for DBP, PSQI scores, or PTSD symptoms. However, the average hostility score was significantly higher $(p=.006)$ for men $(21.5 \pm 1.17)$ than for women $(17.3 \pm 0.96)$.

Zero-order correlations (see Table 2) among the study variables showed that PTSD symptoms were strongly associated with poorer sleep quality $(r(88)=.517, p<.001)$ and higher hostility scores $(r(86)=.492, p<.001)$ in the total sample. These relationships are illustrated in Figures 1 and 2. Age was also positively associated with diastolic blood pressure in the full sample $(r(87)=.221, p=.038)$. In young women (see Table 3 ), PTSD symptoms were associated with high hostility scores $(r(46)=.362, p=.011)$ and poor sleep quality $(r(47)=.303, p=.034)$. In young men, PTSD symptoms were associated with poor sleep quality $(r(39)=$ $.691, p<.001)$ and higher hostility scores $(r(38)=.597, p<$ $.001)$ and were also associated with higher resting diastolic blood pressure $(r(39)=.402, p=.009)$.

Multiple regression analyses were conducted to examine unique contributions of study variables to PTSD symptoms. The models included age, resting diastolic blood pressure, hostility, and sleep quality as independent variables (see Table 4). Three separate sets of regression analyses were conducted, using the total sample and men and women separately. Results indicated that both hostility and sleep quality were independently associated with PTSD symptoms in the total sample $(p<.001)$, and in men $(p<.01)$. Hostility remained a unique correlate of PTSD symptoms in women $(p=.025)$, while the effect of sleep quality revealed a strong trend $(p=.052)$. In men, both sleep quality and hostility remained significant $(p=.01$ and $p<.001$, resp.), whereas 
TABLE 2: Zero-order correlations among study variables in women and men combined.

\begin{tabular}{|c|c|c|c|c|c|c|c|}
\hline & & Age & Sleep quality & DBP & SBP & PTSD symptoms & Hostility \\
\hline \multirow{3}{*}{$\operatorname{Sex}(\operatorname{men}=0$, women $=1)$} & Pearson correlation & -.063 & -.011 & -.051 & $-.557^{* *}$ & -.098 & $-.290^{* *}$ \\
\hline & Sig. (2-tailed) & .555 & .915 & .633 & .000 & .360 & .006 \\
\hline & $N$ & 89 & 91 & 91 & 91 & 90 & 89 \\
\hline \multirow{3}{*}{ Age } & Pearson correlation & & -.070 & $.221^{*}$ & .087 & -.029 & .031 \\
\hline & Sig. (2-tailed) & & .516 & .038 & .417 & .788 & .776 \\
\hline & $N$ & & 89 & 89 & 89 & 88 & 87 \\
\hline \multirow{3}{*}{ Sleep quality } & Pearson correlation & & & $.251^{*}$ & .116 & $.517^{* *}$ & $.270^{*}$ \\
\hline & Sig. (2-tailed) & & & .017 & .272 & .000 & .010 \\
\hline & $N$ & & & 91 & 91 & 90 & 89 \\
\hline \multirow{3}{*}{$\mathrm{DBP}$} & Pearson correlation & & & & $.515^{* *}$ & .202 & .173 \\
\hline & Sig. (2-tailed) & & & & .000 & .056 & .105 \\
\hline & $N$ & & & & 91 & 90 & 89 \\
\hline \multirow{3}{*}{ SBP } & Pearson correlation & & & & & .116 & .163 \\
\hline & Sig. (2-tailed) & & & & & .276 & .126 \\
\hline & $N$ & & & & & 90 & 89 \\
\hline \multirow{3}{*}{ PTSD symptoms } & Pearson correlation & & & & & & $.492^{* *}$ \\
\hline & Sig. (2-tailed) & & & & & & .000 \\
\hline & $N$ & & & & & & 88 \\
\hline
\end{tabular}

** Correlation is significant at the 0.01 level (2-tailed).

${ }^{*}$ Correlation is significant at the 0.05 level (2-tailed).

TABLE 3: Zero-order correlations for women (above diagonal) and men (below diagonal).

\begin{tabular}{|c|c|c|c|c|c|c|c|}
\hline & & Age & Sleep quality & $\mathrm{DBP}$ & SBP & PTSD symptoms & Hostility \\
\hline \multirow{3}{*}{ Age } & Pearson correlation & & -.076 & .176 & .085 & -.150 & -.007 \\
\hline & Sig. (2-tailed) & - & .614 & .236 & .571 & .313 & .966 \\
\hline & $N$ & & 47 & 47 & 47 & 47 & 46 \\
\hline \multirow{3}{*}{ Sleep quality } & Pearson correlation & -.076 & & .135 & -.029 & $.303^{*}$ & .101 \\
\hline & Sig. (2-tailed) & .633 & - & .354 & .845 & .034 & .495 \\
\hline & $N$ & 42 & & 49 & 49 & 49 & 48 \\
\hline \multirow{3}{*}{ DBP } & Pearson correlation & $.308^{*}$ & $.360^{*}$ & & $.683^{* *}$ & -.036 & .047 \\
\hline & Sig. (2-tailed) & .047 & .019 & - & .000 & .805 & .752 \\
\hline & $N$ & 42 & 42 & & 49 & 49 & 48 \\
\hline \multirow{3}{*}{ SBP } & Pearson correlation & .019 & $.329^{*}$ & $.471^{* *}$ & & -.077 & -.048 \\
\hline & Sig. (2-tailed) & .904 & .033 & .002 & - & .601 & .745 \\
\hline & $N$ & 42 & 42 & 42 & & 49 & 48 \\
\hline \multirow{3}{*}{ PTSD symptoms } & Pearson correlation & .126 & $.691^{* *}$ & $.402^{* *}$ & .244 & & $.362^{*}$ \\
\hline & Sig. (2-tailed) & .434 & .000 & .009 & .124 & - & .011 \\
\hline & $N$ & 41 & 41 & 41 & 41 & & 48 \\
\hline \multirow{3}{*}{ Hostility } & Pearson correlation & .048 & $.442^{* *}$ & .285 & .068 & $.597^{* *}$ & \\
\hline & Sig. (2-tailed) & .763 & .004 & .071 & .671 & .000 & - \\
\hline & $N$ & 41 & 41 & 41 & 41 & 40 & \\
\hline
\end{tabular}

${ }^{*}$ Correlation is significant at the 0.05 level (2-tailed).

${ }^{* *}$ Correlation is significant at the 0.01 level (2-tailed).

diastolic blood pressure was no longer significant when both variables were included in the model $(p=.564)$.

Systematic analysis of mediation and moderation [36] indicated that sex is an important moderator of the relation between diastolic blood pressure and PTSD. Moreover, sleep quality and hostility are substantive mediators of the relationship between diastolic blood pressure and PTSD symptoms. Results showed a much stronger relation between sleep and PTSD for men $\left(R^{2}=.48\right)$ and a milder relation for women $\left(R^{2}=.09\right)$. 
TABLE 4: Multiple regression predicting PTSD symptoms from age, sex, diastolic blood pressure, hostility, and sleep quality.

\begin{tabular}{|c|c|c|c|c|c|}
\hline \multirow{2}{*}{ Model } & \multicolumn{2}{|c|}{ Unstandardized coefficients } & \multirow{2}{*}{$\begin{array}{c}\text { Standardized coefficients } \\
\text { Beta }\end{array}$} & \multirow{2}{*}{$t$} & \multirow{2}{*}{ Sig. } \\
\hline & $\mathrm{B}$ & Std. error & & & \\
\hline \multicolumn{6}{|c|}{ Total sample } \\
\hline (Constant) & 6.745 & 11.318 & & .596 & .553 \\
\hline Age & -.030 & .222 & -.012 & -.137 & .892 \\
\hline Sex & .613 & 1.949 & .028 & .315 & .754 \\
\hline DBP & .049 & .174 & .026 & .284 & .777 \\
\hline Hostility & .546 & .141 & .367 & 3.865 & .000 \\
\hline Sleep quality & 1.721 & .385 & .421 & 4.474 & .000 \\
\hline \multicolumn{6}{|c|}{ Men } \\
\hline (Constant) & -13.337 & 15.127 & & -.882 & .384 \\
\hline Age & .508 & .425 & .135 & 1.196 & .240 \\
\hline $\mathrm{DBP}$ & .142 & .244 & .071 & .582 & .564 \\
\hline Hostility & .539 & .197 & .328 & 2.739 & .010 \\
\hline Sleep quality & 2.194 & .514 & .533 & 4.267 & .000 \\
\hline \multicolumn{6}{|c|}{ Women } \\
\hline (Constant) & 27.398 & 16.191 & & 1.692 & .098 \\
\hline Age & -.208 & .262 & -.112 & -.794 & .432 \\
\hline DBP & -.132 & .244 & -.078 & -.542 & .591 \\
\hline Hostility & .465 & .200 & .323 & 2.329 & .025 \\
\hline Sleep quality & 1.151 & .574 & .285 & 2.006 & .052 \\
\hline
\end{tabular}

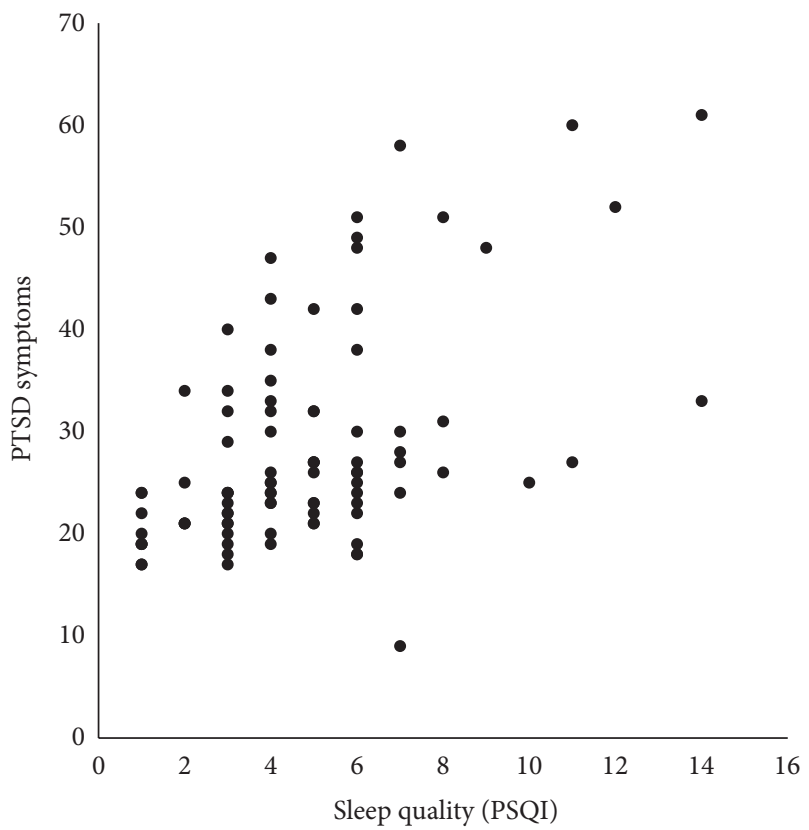

FIGURE 1: Scatter plot of the relationship between sleep quality as measured by the Pittsburgh Sleep Quality Index (PSQI; higher scores indicate poorer quality of sleep) and PTSD Symptoms as measured by the Posttraumatic Stress Disorder Checklist (higher scores indicate more symptoms reported) in men and women combined $(r(88)=0.517, p<.001)$.

\section{Discussion}

The present study was designed to examine the relationships among subclinical PTSD symptoms and several variables

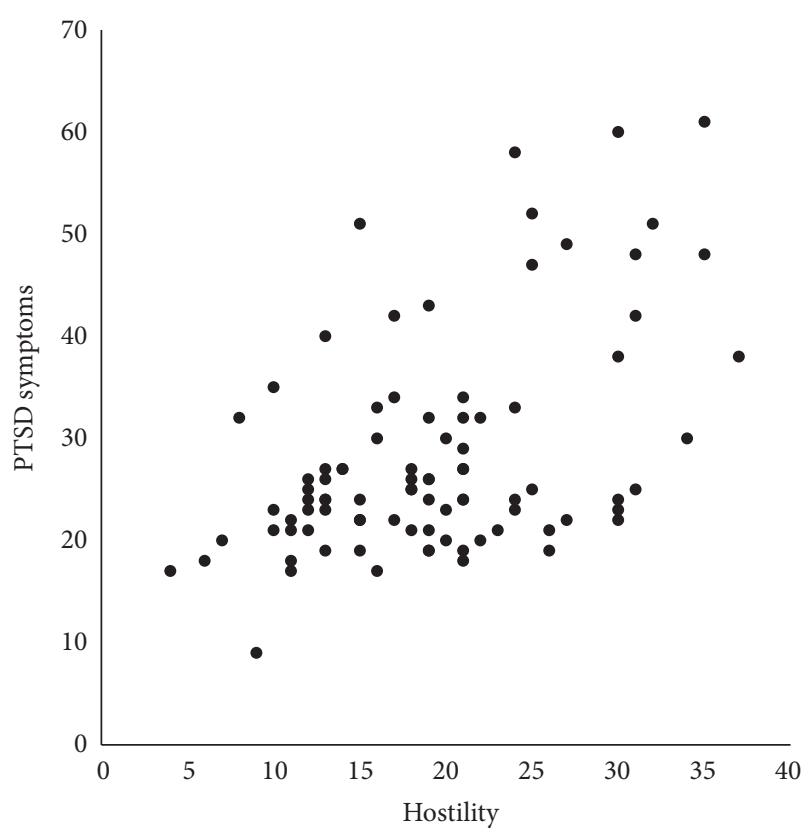

FIGURE 2: Scatter plot of the relationship between hostility as measured by the Cook-Medley Hostility Scale (higher scores indicate higher hostility) and PTSD Symptoms as measured by the Posttraumatic Stress Disorder Checklist (higher scores indicate more symptoms reported) in men and women combined $(r(86)=$ 0.492, $p<.001)$.

linked to both frank PTSD and the basic psychobiological adaptation to stress in young adults. Subclinical PTSD symptoms have been studied in survivors of intimate partner 
violence [37], Vietnam veterans [38], and young adults [39], among others, but these studies have not focused on factors directly related to the psychobiology of stress and arousal. However, preclinical studies of the relationship between PTSD-associated symptoms, blood pressure, sleep quality, and hostility are important for several reasons. First, relatively little work has been done to characterize these relationships in the normal population, a scientific step necessary to fully understand the nature of biobehavioral processes involved in the etiology of PTSD physio- and psychopathology upon exposure to traumatic stress. Second, a better understanding of the basic effects of common stress-associated biobehavioral variables may provide some insight into preclinical factors that may lead to vulnerability or increased risk of PTSD development. And third, a better understanding of stress mechanisms that interact with PTSD symptomology may provide insight into new strategies to treat PTSD and its underlying cardiovascular comorbidities. Even more importantly these findings may potentially inform new strategies to develop resilience in, for example, combat troops prior to deployments with high potential for exposure to combatrelated trauma.

There are several remarkable results from the current study. Diastolic blood pressure is a substantive predictor of PTSD symptoms in men, but not in women. The relationship between diastolic blood pressure and PTSD in men is strongly mediated by sleep quality and to a lesser extent by hostility. In women, sleep quality and hostility predict PTSD (with hostility being a slightly stronger predictor), but BP is not related to either of these, nor to PTSD symptom expression. These findings are particularly interesting since there is a significant literature linking sleep quality and hostility with (1) psychophysiological responses to acute and chronic stress and (2) risk for cardiovascular diseases often found comorbid with PTSD.

4.1. Sleep Quality. Our finding that poor sleep quality was associated with higher blood pressure and PTSD symptoms is consistent with prior research examining autonomic dysregulation underlying both sleep dysfunction and physiological responses to stress. Several investigations from our laboratory and others have found that sleep quality is associated with autonomic dysregulation and elevated blood pressure. For example, epidemiologic studies have documented an association between blood pressure elevations and both shorter sleep duration and lower sleep maintenance [40-42]. Laboratory evidence suggests that increased sympathetic nervous system activity is a mechanism underlying the association between poor sleep quality and blood pressure elevations [43-45]. Studies of sleep deprivation from our laboratory [15] suggest that acute sleep deprivation can contribute to blood pressure elevations in persons at risk for hypertension. Other work indicates that the relationship between sleep deprivation and blood pressure is associated with increased autonomic arousal. For example, in a microneurographic study, Ogawa and associates [44] indicate that 24 hours of total sleep deprivation elevates blood pressure through resetting of arterial baroreflexes. Moreover, persons with insomnia show reduced heart period and heart period variability, with increased low frequency and decreased high frequency power spectra, suggesting that sleep deprivation may alter parasympathetic tone on the heart [45]. Therefore, chronic sleep deprivation, whether from short sleep duration or circadian desynchronization, appears to alter the balance between the sympathetic and parasympathetic nervous systems.

4.2. Hostility. Our finding that hostility was associated with sleep quality, blood pressure, and PTSD symptoms adds to the literature on potential psychosocial mechanisms accounting for the relation between stress responses, autonomic dysregulation, and symptom expression. Meta-analysis has documented a large effect size for the association between hostility and PTSD, which increased over time since the traumatic event [5]. Individuals high on trait hostility may be particularly vulnerable to developing PTSD symptoms and sympathetic nervous system overactivation [46]. The hostility literature also indicates an intimate relationship between hostility and both circulatory disease risk [25] and blood pressure reactivity [24]. Thus, our findings that hostility could account for the relationship between blood pressure and PTSD symptoms in men are consistent with existing literature.

4.3. Autonomic Nervous System Arousal. The increased arousal resulting from hostility and poor sleep quality may operate in synergy with the physiological response to traumatic stress in production of PTSD symptoms. PTSD symptoms are associated with both hostility and sleep disturbance, which, based on our current findings, could account for the autonomic dysregulation and increased risk for hypertension observed in individuals with PTSD. PTSD involves chronic overactivation of the sympathetic nervous system [22], in addition to concomitant alterations in parasympathetic control of the heart. It is therefore not surprising that individuals with PTSD exhibit higher baseline heart rate and blood pressure values in comparison to individuals without PTSD [2-4]. The finding that hostility and sleep disturbance were related to PTSD symptoms in the overall sample, and that blood pressure was related to both sleep disturbance and PTSD symptoms in men, supports the theory that PTSD involves sympathetic nervous system overactivation. Our data suggest that, at least in men, the relationship between resting blood pressure and PTSD symptoms is secondary to the effect of poor sleep quality and hostility. Nevertheless, the precise causal pathways cannot be definitively determined from the current methodology. Additional future work such as randomized trials of both sleep-enhancing interventions and cognitive restructuring of hostile attitudes is recommended to better understand the causal nature of the relationships among sleep quality, hostility, blood pressure control, and PTSD symptom expression in populations who may be at risk for subsequent exposure to traumatic stressors.

4.4. Potential Efficacy of Stress Management. Evidence for the potential efficacy of stress management comes from research showing that cognitive behavioral stress management (CBSM) training, especially in small groups, reduces 
hostility and related psychosocial and physiological characteristics. For example, Bishop and coworkers found that psychosocial skills training reduced anger as well as depression, social isolation, and $\mathrm{BP}$ at rest and during anger recall stress in patients following coronary artery bypass graft [47]. Moreover, two independent randomized, controlled trials showed that cognitive behavioral therapy reduced mortality in patients with coronary heart disease [48, 49]. An observational trial in multiple corporate worksites showed that such training produced reductions in hostility that were maintained six months following the completion of training [50]. Additional future work such as randomized trials of both sleep-enhancing interventions and cognitive restructuring of hostile attitudes is recommended to better understand the causal nature of the relationships among sleep quality, hostility, blood pressure control, and PTSD symptom expression in men and women without a reported history of frank PTSD.

4.5. Limitations. This study does not directly address causal connections among study variables. It is likely that the relationships among the study variables are bidirectional in nature, and thus causal influences may be difficult to fully characterize. Longitudinal studies are needed to investigate the nature of these relationships over time. Another limitation is that the study sample was not sufficient to examine the potential effects of race and/or ethnicity. While the current subclinical sample is valuable for examination of precursors to PTSD symptom expression, the results may not generalize to other age groups and/or all racial, ethnic, and socioeconomic populations. Furthermore, it is possible that individuals meeting clinical criteria for PTSD are subject to additional autonomic irregularities and other psychosocial risk factors compared with the subclinical population included in this study. On the other hand, effect sizes in this study may represent underestimates of the effects that may be observed in clinical populations. Finally, caution should be taken in etiologic interpretation of our findings, as it can be difficult to disentangle these constructs in causally meaningful ways without further and more extensive study.

\section{Conclusions}

In summary, these findings suggest that poor sleep quality and hostility are associated with subclinical PTSD symptoms in healthy young men and women without a known history of PTSD. In young men, elevated blood pressure was associated with more PTSD symptoms, but this effect appeared to be accounted for, at least in part, by both sleep quality and hostility. Thus sleep quality and hostility may underlie some of the hyperarousal and autonomic nervous system disturbance in the expression of clinical PTSD symptoms, at least in men.

The fact that both hostility and sleep disturbance were associated with PTSD symptoms independent of blood pressure suggests that they may represent underlying psychobiological mechanisms by which trauma relates to hyperarousal. Sleep quality and hostility accounted for the relation between diastolic blood pressure and PTSD symptoms in men but not women, so it is possible that different psychobiological processes underlie stress responses and autonomic dysregulation in men versus women. For example, researchers have described an oxytocin-associated "tend and befriend" approach to stress among women, in addition to the traditional fight-or-flight response that is more prevalent in men [51]. Future research is necessary to further explore gender differences in responses to chronic stress that may contribute to PTSD risk. Finally, these data raise the possibility that behavioral interventions to enhance sleep quality and restructure hostile attitudes could potentially serve as effective interventions for PTSD and its underlying cardiovascular comorbidities. If further work verifies these causal mechanisms, then our data suggest that interventions directed at sleep quality and hostile attitudes may relieve symptoms in persons with PTSD and may possibly provide new strategies for building resilience in persons who are likely to be exposed to traumatic stress in the future.

\section{Competing Interests}

There are no competing interests for any of the authors.

\section{Acknowledgments}

The authors gratefully acknowledge their research staff for their assistance in data gathering for the study and data management. These individuals include Miranda Rodriguez, Tracy McGee, Chelsea Green, Stephanie Kinard, and Jesse Hayes.

\section{References}

[1] American Psychiatric Association, Diagnostic and Statistical Manual of Mental Disorders (DSM-5), American Psychiatric Publications, 2013.

[2] E. B. Blanchard, "Elevated basal levels of cardiovascular responses in Vietnam veterans with PTSD: a health problem in the making?" Journal of Anxiety Disorders, vol. 4, no. 3, pp. 233237, 1990.

[3] T. C. Buckley and D. G. Kaloupek, "A meta-analytic examination of basal cardiovascular activity in posttraumatic stress disorder," Psychosomatic Medicine, vol. 63, no. 4, pp. 585-594, 2001.

[4] M. Y. Muraoka, J. G. Carlson, and C. M. Chemtob, “Twentyfour-hour ambulatory blood pressure and heart rate monitoring in combat-related posttraumatic stress disorder," Journal of Traumatic Stress, vol. 11, no. 3, pp. 473-484, 1998.

[5] U. Orth and E. Wieland, "Anger, hostility, and posttraumatic stress disorder in trauma-exposed adults: a meta-analysis," Journal of Consulting and Clinical Psychology, vol. 74, no. 4, pp. 698-706, 2006.

[6] B. A. Van der Kolk, "The psychobiology and psychopharmacology of PTSD," Human Psychopharmacology: Clinical and Experimental, vol. 16, no. 1, pp. S49-S64, 2001.

[7] T. G. M. Vrijkotte, L. J. P. Van Doornen, and E. J. C. De Geus, "Effects of work stress on ambulatory blood pressure, heart rate, and heart rate variability," Hypertension, vol. 35 , no. 4, pp. $880-$ $886,2000$. 
[8] C. Drake, G. Richardson, T. Roehrs, H. Scofield, and T. Roth, "Vulnerability to stress-related sleep disturbance and hyperarousal," Sleep, vol. 27, no. 2, pp. 285-291, 2004.

[9] S. Bruehl, J. A. McCubbin, C. R. Carlson et al., "The psychobiology of hostility: possible endogenous opioid mechanisms," International Journal of Behavioral Medicine, vol. 3, no. 2, pp. 163-176, 1996.

[10] K. A. Lawler, T. L. Harralson, C. A. Armstead, and L. A. Schmied, "Gender and cardiovascular responses: what is the role of hostility?" Journal of Psychosomatic Research, vol. 37, no. 6, pp. 603-613, 1993.

[11] T. Wu, H. Snieder, and E. de Geus, "Genetic influences on cardiovascular stress reactivity," Neuroscience and Biobehavioral Reviews, vol. 35, no. 1, pp. 58-68, 2010.

[12] G. Weidner, R. Friend, T. J. Ficarrotto, and N. R. Mendell, "Hostility and cardiovascular reactivity to stress in women and men," Psychosomatic Medicine, vol. 51, no. 1, pp. 36-45, 1989.

[13] M. F. Dollard and A. H. Winefield, "A test of the demandcontrol/support model of work stress in correctional officers," Journal of Occupational Health Psychology, vol. 3, no. 3, pp. 243264, 1998.

[14] J. A. McCubbin, R. Cheung, T. B. Montgomery, R. Bulbulian, and J. F. Wilson, "Aerobic fitness and opioidergic inhibition of cardiovascular stress reactivity," Psychophysiology, vol. 29, no. 6, pp. 687-697, 1992.

[15] J. A. McCubbin, J. J. Pilcher, and D. D. Moore, "Blood pressure increases during a simulated night shift in persons at risk for hypertension," International Journal of Behavioral Medicine, vol. 17, no. 4, pp. 314-320, 2010.

[16] C. Heim, D. J. Newport, R. Bonsall, A. H. Miller, and C. B. Nemeroff, "Altered pituitary-adrenal axis responses to provocative challenge tests in adult survivors of childhood abuse," The American Journal of Psychiatry, vol. 158, no. 4, pp. 575-581, 2001.

[17] P. Ibarra, S. P. Bruehl, J. A. McCubbin et al., "An unusual reaction to opioid blockade with naltrexone in a case of post-traumatic stress disorder," Journal of Traumatic Stress, vol. 7, no. 2, pp. 303309, 1994.

[18] B. A. van der Kolk, "The psychobiology and psychopharmacology of PTSD," Human Psychopharmacology: Clinical and Experimental, vol. 16, no. 1, pp. S49-S64, 2001.

[19] A. C. McFarlane, "Posttraumatic stress disorder: a model of the longitudinal course and the role of risk factors," Journal of Clinical Psychiatry, vol. 61, no. 5, pp. 15-23, 2000.

[20] S. M. Southwick, S. R. Paige, C. A. Morgan, J. D. Bremner, J. H. Krystal, and D. S. Charney, "Adrenergic and serotonergic abnormalities," Seminars in Clinical Neuropsychiatry, vol. 4, pp. 242-248, 1999.

[21] M. E. McFall, R. C. Veith, and M. M. Murburg, "Basal sympathoadrenal function in posttraumatic distress disorder," Biological Psychiatry, vol. 31, no. 10, pp. 1050-1056, 1992.

[22] M. M. Murburg, M. E. McFall, G. N. Ko, and R. C. Veith, "Stressinduced alterations in plasma catecholamines and sympathetic nervous system function in PTSD," in Catecholamine Function in Postraumatic Stress Disorder: Emerging Concepts, pp. 189202, 1994.

[23] J. L. Kibler, K. Joshi, and M. Ma, "Hypertension in relation to posttraumatic stress disorder and depression in the us national comorbidity survey," Behavioral Medicine, vol. 34, no. 4, pp. 125131, 2009.

[24] J. C. Beckham, A. M. Flood, M. F. Dennis, and P. S. Calhoun, "Ambulatory cardiovascular activity and hostility ratings in women with chronic posttraumatic stress disorder," Biological Psychiatry, vol. 65, no. 3, pp. 268-272, 2009.

[25] J. C. Barefoot, W. G. Dahlstrom, and R. B. Williams, "Hostility, CHD incidence, and total mortality: a 25 -year follow-up study of 255 physicians," Psychosomatic Medicine, vol. 45, no. 1, pp. 5963, 1983.

[26] T. G. Pickering, J. E. Hall, L. J. Appel et al., "Recommendations for blood pressure measurement in humans and experimental animals: part 1: blood pressure measurement in humans: a statement for professionals from the subcommittee of professional and public education of the American Heart Association Council on High Blood Pressure Research," Hypertension, vol. 45, no. 1, pp. 142-161, 2005.

[27] F. W. Weathers, B. T. Litz, D. Herman, J. Huska, and T. Keane, The PTSD Checklist-Civilian Version (PCL-C), National Center for PTSD, Boston, Mass, USA, 1994.

[28] D. J. Buysse, M. L. Hall, P. J. Strollo et al., "Relationships between the Pittsburgh Sleep Quality Index (PSQI), Epworth Sleepiness Scale (ESS), and clinical/polysomnographic measures in a community sample," Journal of Clinical Sleep Medicine, vol. 4, no. 6, pp. 563-571, 2008.

[29] J. C. Barefoot, K. A. Dodge, B. L. Peterson, W. G. Dahlstrom, and R. B. Williams Jr., "The Cook-Medley hostility scale: item content and ability to predict survival," Psychosomatic Medicine, vol. 51, no. 1, pp. 46-57, 1989.

[30] K. J. Ruggiero, K. Del Ben, J. R. Scotti, and A. E. Rabalais, "Psychometric properties of the PTSD checklist-civilian version," Journal of Traumatic Stress, vol. 16, no. 5, pp. 495-502, 2003.

[31] E. B. Blanchard, J. Jones-Alexander, T. C. Buckley, and C. A. Forneris, "Psychometric properties of the PTSD checklist (PCL)," Behaviour Research and Therapy, vol. 34, no. 8, pp. 669673, 1996.

[32] J. R. Freedy and C. D. Brock, "Spotting- and treating-PTSD in primary care," Journal of Family Practice, vol. 59, no. 2, pp. 7580, 2010.

[33] M. E. McDevitt-Murphy, F. W. Weathers, J. W. Adkins, and J. B. Daniels, "Use of the personality assessment inventory in assessment of posttraumatic stress disorder in women," Journal of Psychopathology and Behavioral Assessment, vol. 27, no. 2, pp. 57-65, 2005.

[34] Y. Huang, W. Mai, Y. Hu et al., "Poor sleep quality, stress status, and sympathetic nervous system activation in nondipping hypertension," Blood Pressure Monitoring, vol. 16, no. 3, pp. 117123, 2011.

[35] T. W. Smith and K. D. Frohm, "What's so unhealthy about hostility? Construct validity and psychosocial correlates of the Cook and Medley Ho scale," Health Psychology, vol. 4, no. 6, pp. 503-520, 1985.

[36] R. M. Baron and D. A. Kenny, “The moderator-mediator variable distinction in social psychological research. conceptual, strategic, and statistical considerations," Journal of Personality and Social Psychology, vol. 5, no. 6, pp. 1173-1182, 1986.

[37] A. L. Coker, R. Weston, D. L. Creson, B. Justice, and P. Blakeney, "PTSD symptoms among men and women survivors of intimate partner violence: the role of risk and protective factors," Violence and Victims, vol. 20, no. 6, pp. 625-643, 2005.

[38] M. M. Steenkamp, A. Nickerson, S. Maguen, B. D. Dickstein, W. P. Nash, and B. T. Litz, "Latent classes of PTSD symptoms in Vietnam veterans," Behavior Modification, vol. 36, no. 6, pp. 857-874, 2012.

[39] J. M. Smyth, J. R. Hockemeyer, K. E. Heron, S. A. Wonderlich, and J. W. Pennebaker, "Prevalence, type, disclosure, and severity 
of adverse life events in college students," Journal of American College Health, vol. 57, no. 1, pp. 69-76, 2008.

[40] J. E. Gangwisch, S. B. Heymsfield, B. Boden-Albala et al., "Short sleep duration as a risk factor for hypertension: analyses of the first National Health and Nutrition Examination survey," Hypertension, vol. 47, no. 5, pp. 833-839, 2006.

[41] D. J. Gottlieb, S. Redline, F. J. Nieto et al., "Association of usual sleep duration with hypertension: the Sleep Heart Health Study," Sleep, vol. 29, no. 8, pp. 1009-1014, 2006.

[42] K. L. Knutson, E. Van Cauter, P. J. Rathouz et al., "Association between sleep and blood pressure in midlife: The CARDIA Sleep Study," Archives of Internal Medicine, vol. 169, no. 11, pp. 1055-1061, 2009.

[43] K. Spiegel, R. Leproult, and E. Van Cauter, "Impact of sleep debt on metabolic and endocrine function," The Lancet, vol. 354, no. 9188, pp. 1435-1439, 1999.

[44] Y. Ogawa, T. Kanbayashi, Y. Saito et al., “Total sleep deprivation elevates blood pressure through arterial baroreflex resetting: a study with microneurographic technique," Sleep, vol. 26, no. 8 , pp. 986-989, 2003.

[45] M. H. Bonnet and D. L. Arand, "Heart rate variability in insomniacs and matched normal sleepers," Psychosomatic Medicine, vol. 60 , no. 5, pp. 610-615, 1998.

[46] M. C. Davis, K. A. Matthews, and C. E. McGrath, "Hostile attitudes predict elevated vascular resistance during interpersonal stress in men and women," Psychosomatic Medicine, vol. 62, no. 1, pp. 17-25, 2000.

[47] G. D. Bishop, D. Kaur, V. L. M. Tan, Y.-L. Chua, S.-M. Liew, and K.-H. Mak, "Effects of a psychosocial skills training workshop on psychophysiological and psychosocial risk in patients undergoing coronary artery bypass grafting," American Heart Journal, vol. 150, no. 3, pp. 602-609, 2005.

[48] K. Orth-Gomér, N. Schneiderman, H.-X. Wang, C. Walldin, M. Blom, and T. Jernberg, "Stress reduction prolongs life in women with coronary disease: the Stockholm women's intervention trial for coronary heart disease (SWITCHD)," Circulation: Cardiovascular Quality and Outcomes, vol. 2, no. 1, pp. 25-32, 2009.

[49] M. Gulliksson, G. Burell, B. Vessby, L. Lundin, H. Toss, and K. Svärdsudd, "Randomized controlled trial of cognitive behavioral therapy vs standard treatment to prevent recurrent cardiovascular events in patients with coronary heart disease: secondary prevention in Uppsala primary health care project (SUPRIM)," Archives of Internal Medicine, vol. 171, no. 2, pp. 134-140, 2011.

[50] V. P. Williams, S. L. Brenner, M. J. Helms, and R. B. Williams, "Coping skills training to reduce psychosocial risk factors for medical disorders: a field trial evaluating effectiveness in multiple worksites," Journal of Occupational Health, vol. 51, no. 5, pp. 437-442, 2009.

[51] S. E. Taylor, L. C. Klein, B. P. Lewis, T. L. Gruenewald, R. A. R. Gurung, and J. A. Updegraff, "Biobehavioral responses to stress in females: tend-and-befriend, not fight-or-flight," Psychological Review, vol. 107, no. 3, pp. 411-429, 2000. 


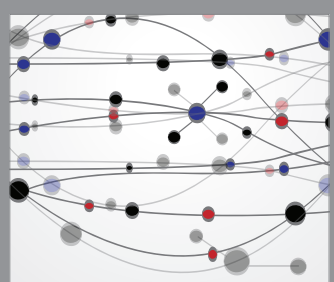

The Scientific World Journal
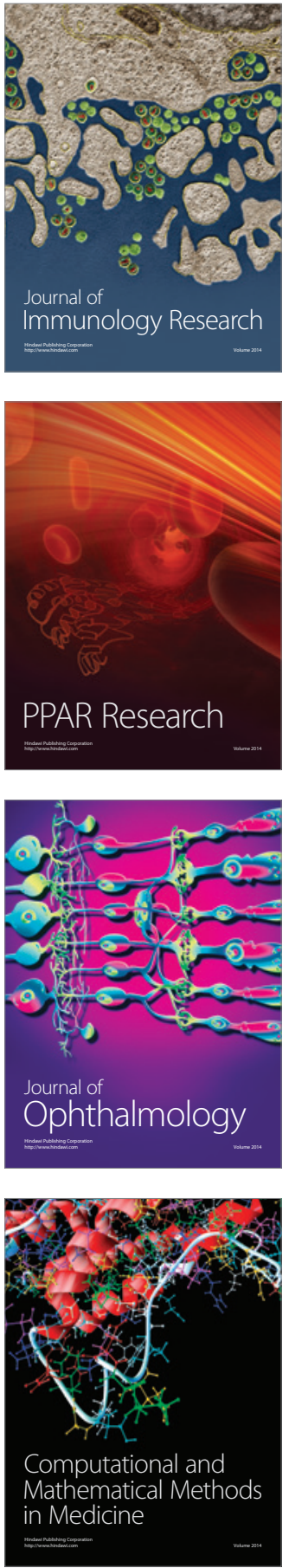

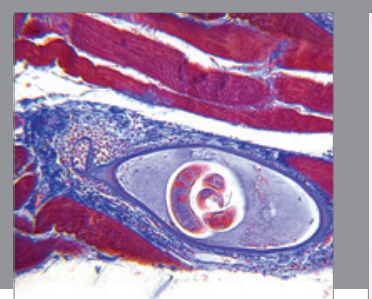

Gastroenterology Research and Practice

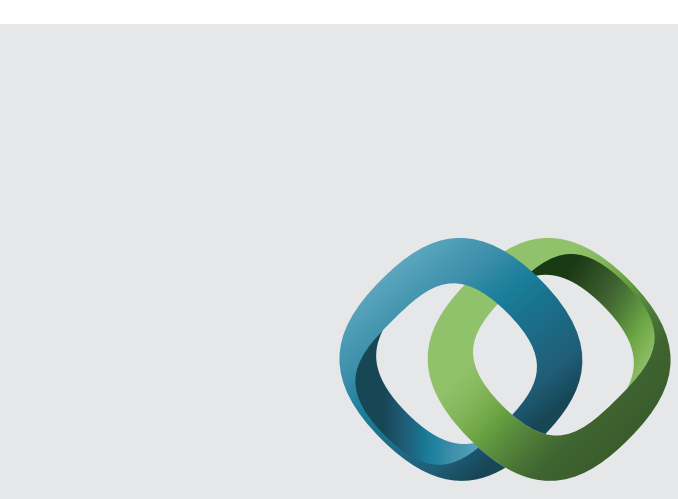

\section{Hindawi}

Submit your manuscripts at

http://www.hindawi.com
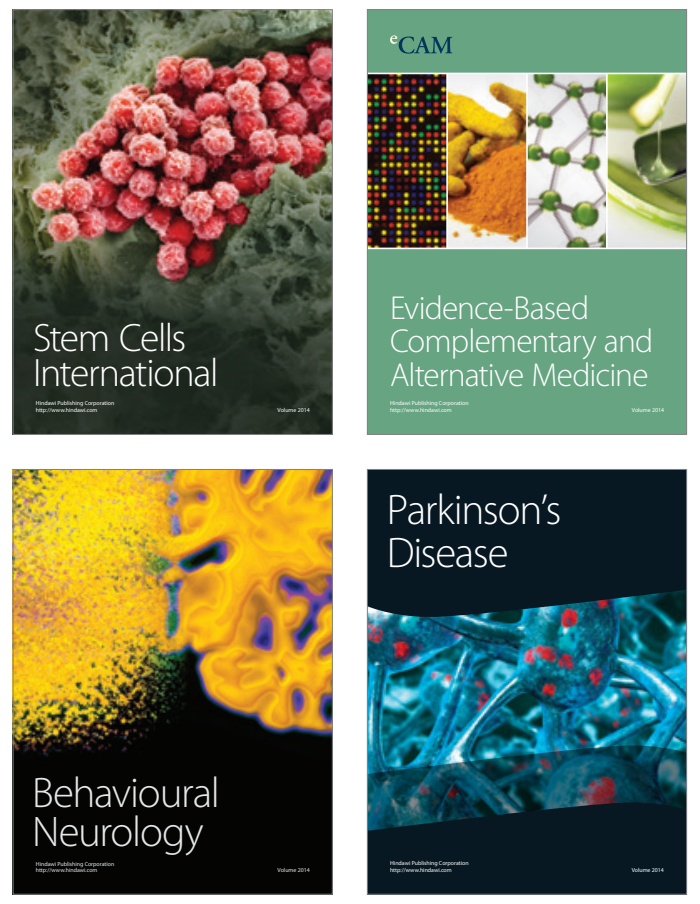
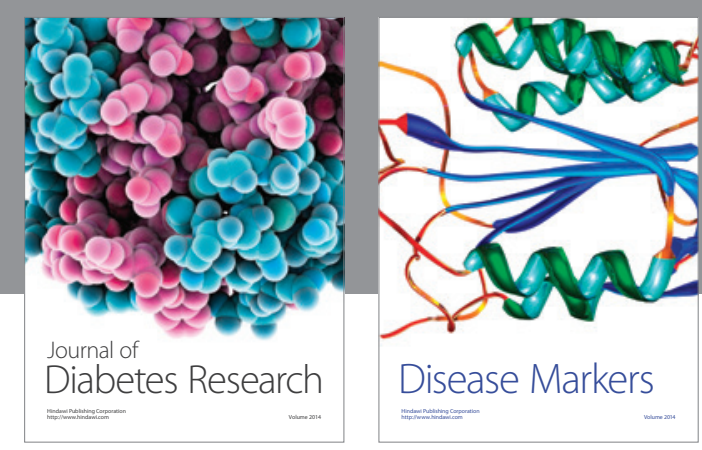

Disease Markers
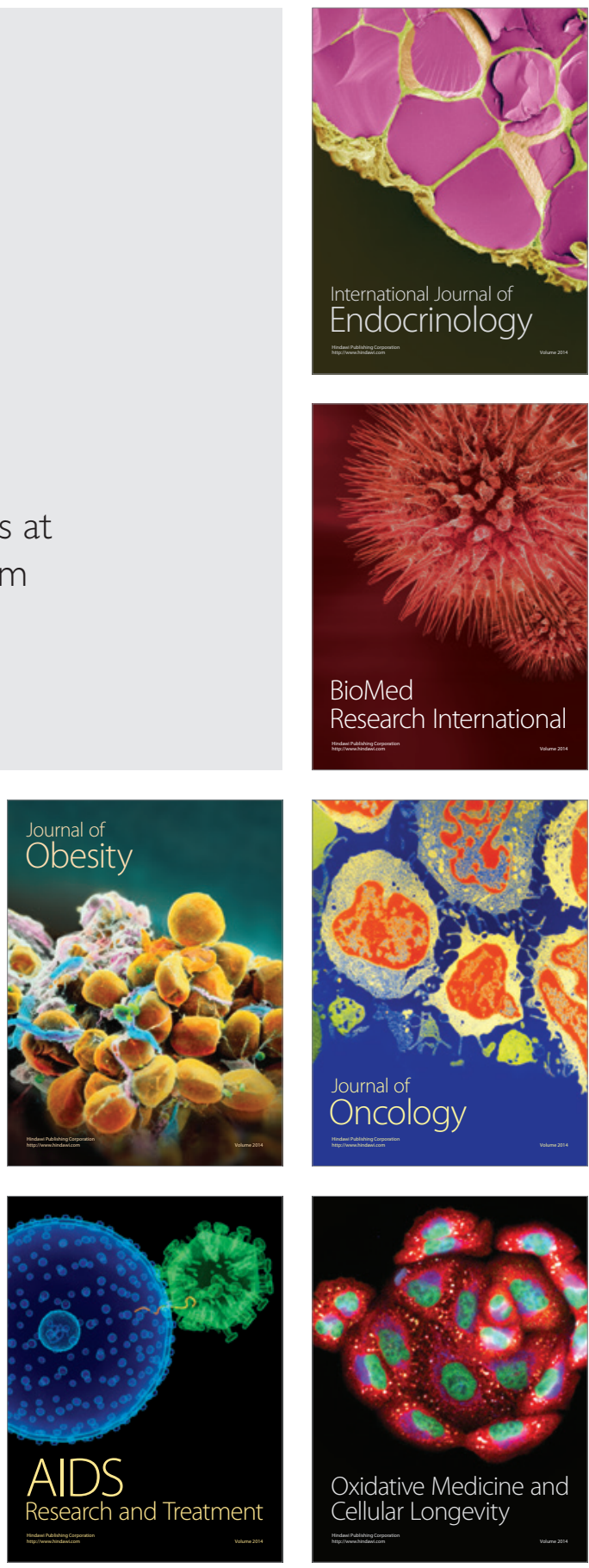